\title{
Histórias de vida e biografização: pesquisa sobre as marcas formadoras de professores da região sudeste do estado de Goiás através dos memoriais de formação
}

\author{
Cláudia Machado* \\ Universidade Federal de Goiás \\ Wolney Honório Filho** \\ Universidade Federal de Goiás
}

Resumo Este artigo aborda os resultados da pesquisa realizada no Estágio de Pós-Doutorado, intitulada "Histórias de Vida e Biografização: Memoriais de Alunas do Curso de Pedagogia da UFG/Regional Catalão 2015”, desenvolvido no Programa de Pós-Graduação em Educação da Universidade Federal de Goiás - Regional Catalão, vinculada à Linha de Pesquisa "História e Culturas Educacionais". A proposta de pesquisa foi a análise do sentido das marcas formadoras que profissionais da educação em formação produzem quando são submetidos à escrita de memoriais. Como questões de pesquisa investigou-se a relação entre memória e formação docente e qual o movimento no desenvolvimento pessoal de construção identitária. Utilizamos como referencial teórico-metodológico as Pesquisas (Auto)Biográficas. A metodologia desenvolvida foi a leitura de 35 memoriais de formação para análise dos relatos dos alunos e das alunas, durante o ano de 2015. Concluímos que a escrita dos memoriais possibilitaram, entre outros aspectos, uma descoberta de como as vivências de sua formação acadêmica e as relações com as pessoas podem determinar quem somos como profissionais da educação.

PALAVRAS-CHAVE: Memorial; Formação de professores; Marcas formadoras. 
Stories of life and biography: research on the training brands of teachers of the southeastern region of the state of goiás through formation memories

\begin{abstract}
This article addresses the results of the research carried out in the post-doctoral stage, entitled "Life Stories and Biography: Memorials of Students of the Pedagogy Course of UFG / Regional Catalão - 2015", developed in the Postgraduate Program in Education of the University Federal de Goiás - Regional Catalão, linked to the Research Line "History and Educational Cultures". The research proposal was to analyze the meaning of the formative marks that professionals of the education in formation produce when they are submitted to the writing of memorials. As research questions investigated the relationship between memory and teacher training and what the movement in the personal development of identity construction. We use as theoretical-methodological reference the (Auto) Biographical Searches. The methodology developed was the reading of 35 training memorials to analyze the reports of the students during the year 2015 . We conclude that the writing of the memorials enabled, among other aspects, a discovery of how the experiences of their academic and relationships with people can determine who we are as education professionals.
\end{abstract}

KEYWORDS: Memorial; Teacher formation; Shaping brands.

\title{
Marcas formadoras e memoriais de alunas e alunos
}

Ao narrar sua própria história, a pessoa procura dar sentido às experiências e, nesse percurso, constrói outra representação de si: reinventa-se. (PASSEGGI, 2011, p. 148).

Este texto é fruto da pesquisa realizada no Estágio de Pós-Doutorado, intitulada "Histórias de Vida e Biografização: Memoriais de Alunas do Curso de Pedagogia da UFG/Regional Catalão - 2015". Nele, refletimos sobre a relação entre memória e formação docente, com base nos memoriais de 29 alunas e de 06 alunos da Disciplina de Núcleo Livre, "Memorial e Formação de Professores", do Curso de Pedagogia $^{1}$, da Universidade Federal de Goiás - Regional Catalão, perfazendo um total de 35 memoriais, durante o ano de 2015.

Os Memoriais de Formação dos educadores permite a construção de subsídios de propostas fundamentais para a formação de professores e para profissionalização docente. A presente investigação baseia-se na ideia de processo de formação continuada, visando dar sentido ao trabalho destes educadores enquanto profissionais com pensamento reflexivo, crítico e transformador da sua própria prática. Dentro dessa perspectiva, trabalhamos na presente pesquisa com as pessoas como ensinam Santamarina e Marinas (1994, p.282), não no sentido estrito de sua representatividade amostral, já que não objetivamos desvendar o modo como se distribuem pela população investigada, as opiniões ou respostas, mas, sim, os sentidos que os educadores 
imprimiram ou imprimem a suas vivências e práticas, fenômeno pelo qual as vivências reflexionadas tornam-se, finalmente, experiências.

Para o desenvolvimento da pesquisa seguindo os estudos de António Nóvoa e Mathias Finger (2010), Gastón Pineau (1988), Marie-Chistine Josso (2004, 2006a, 2006b, 2007, 2010a, 2010b), Marie-Chistine Delory-Momberger (2012), Maria Helena Menna Barreto Abrahão (2006, 2011), Elizeu Clementino Souza (2006, 2016), Maria da Conceição Passeggi (2011,2015), entre outros.

O procedimento para a escrita dos memoriais, inicialmente, deu-se através do exercício de contar, oralmente, a história de sua vida e de sua formação escolar. Posteriormente, passaram para a escrita de seus memoriais, tendo em vista a escolha por determinado curso de graduação, entre outros aspectos. Logo em seguida, foram indicados os textos de leitura para aprofundamento da temática.

Souza (2016, p. 72) nos diz que:

A pesquisa biográfica é considerada, simultaneamente, um meio de investigação e um instrumento de formação, e é, justamente, essa dupla função que justifica a utilização do método no domínio das humanidades, nas ciências sociais e nas ciências da educação. Como investigação, essa abordagem contribui para apreensão do cotidiano, do habitus, de questões identitárias, pessoais, profissionais, além de se constituir num dispositivo fértil que possibilita apreender processos de aprendizagem e de conhecimento-formação, através das experiências e modos como narramos as nossas histórias individuais e coletivas.

O autor enfatiza a pesquisa biográfica como meio de "investigação e instrumento de formação". Trabalhar com memorial, a sua produção, em sala de aula tem essas duas dimensões, pedagógicas e científicas.

Passegui (2015) também nos fala sobre o conhecimento do universo de formação de professores através do estudo de memoriais de formação. Com relação à narrativa de alunas e alunos, concordamos com a autora que ao longo do processo de elaboração dos memoriais, a "ressignificação dos saberes conceituais, práticos e identitários" evolui basicamente dentro de quatro movimentos: o primeiro representa a entrada do autor no universo discursivo onde deve inscrever a sua própria história; o segundo corresponde à descoberta do eu-narrador que coincide com a autoconsciência das transformações de suas práticas; o terceiro corresponde à conclusão do memorial que coincide com a apropriação de uma nova identidade; no final, encontram-se os ideais humanísticos e éticos, revelando um ser humano satisfeito consigo mesmo, motivado a continuar aprendendo. (PASSEGUI, 2015, p. 14).

De fato, os memoriais são um meio singular e importante de acessarmos o universo de sua formação.

Eles sugerem que na medida em que narra a história de sua formação, o professor reinventa-se a si-mesmo conduzido pela auto-reflexão sobre três tipos de saberes: o saber conceitual (teórico), o saber fazer (prática docente e prática de escrita) e o saber ser (consciência 
identitária). A (re)construção identitária estaria, portanto, intimamente relacionada à forma como esses três tipos de saberes vão sendo reconceitualizados na e pela escrita, alicerçada nas representações individuais, crenças e valores que têm os professores sobre eles mesmos (ao se autoavaliarem), sobre os discursos formadores (quando a eles aderem) e sobre suas expectativas face ao processo formativo (quando se autodenominam como "mediadores" e sonham com uma nova escola pública). (PASSEGUI, 2015, p. 13).

"Marca Formadora”, aqui, conforme está no título deste artigo, é concebida como um carimbo, um sinal, uma cicatriz que fica em nós, nos distingue dos outros, nos nomeia, não se relaciona nem com o bem, nem com o mal, simplesmente existe, nos denomina e é denominada por nós. Essa marca não tem forma definida, nem nome, vai mudando e mudando, quando você percebe, já é outro desenho e tem uma nova forma. Essas marcas influenciaram e foram influenciadas por nossa professoralidade - como vamos elaborando esta arte de ser professora, não como uma identidade do lugar-comum, mas como a nossa vida cotidiana processa estas experiências. Nesse sentido, entendemos, com Bolzan (2008, p.110), que a professoralidade é:

Um processo que implica não só o domínio de conhecimentos, de saberes, de fazeres de determinado campo, mas também a sensibilidade do docente como pessoa e profissional em termos de atitudes e valores, tendo a reflexão como componente intrínseco ao processo de ensinar, de aprender, de formar-se e, consequentemente, de desenhar sua própria trajetória.

Evidente que este processo é absolutamente pessoal e único, mas, ao mesmo tempo, atravessou e foi atravessado literalmente por quem cruzou o meu caminho (BOLZAN, 2001, 2002). Ao discutir a atitude do docente formador do futuro professor, enquanto articuladora do espaço para as experiências de formação do professor da escola de educação básica, para Ferreira (2010) no processo de avaliação e reflexão das práticas já vivenciadas no cotidiano do trabalho profissional, poderemos ver nessas práticas as nossas marcas formadoras. $\mathrm{O}$ memorial de formação tem possibilidade de ser uma forma de revisitar pela narrativa de sua prática as suas marcas formadoras. Essas marcas podem surgir das práticas que obtiveram resultados positivos no desenvolvimento e crescimento pessoal e profissional, como daquelas que não foram tão positivas. O importante é a atitude que assumimos perante as marcas que identificamos e nossa capacidade de nos questionarmos para apreendermos as experiências formadoras de tudo que vivemos.

Deve-se salientar que é necessário um descerramento sobre si, um expor-se para os outros e para o mundo, um desvelar-se para uma ampliação de nossas aprendizagens. Ou seja, com o exercício da narrativa instaura-se a possibilidade de troca através de um diálogo com as diferentes práticas educativas, aprende-se na e com a prática sobre o que pensamos e a forma como agimos, como argumenta Ferreira (2010, p. 15): "as pontes entre as disciplinas ao revisitar o velho nas práticas já consolidadas, aprende-se na abertura ao novo a identificação ou o reconhecimento do que já vivemos”, na busca da construção de nossa professoralidade. 
A "professoralidade", conforme Pereira (2000, p. 38), é uma escolha feita seguindo um modelo, mas uma "diferença que o sujeito produz em si". Essa diferença representa uma vontade de mudar, representa convicções. A escolha pela docência não pode ser puramente influenciada por um modelo social, mas por algo próprio do indivíduo:

A professoralidade é o jeito, o modo de ser que tenho alimentado, como via fundamental, tanto para navegar em meu campo individual quanto para me colocar dentro da coletividade. Há tempos ela ressoou com mais força, invadiu e eu pude pressenti-la, com toda sua intensidade. Propositalmente, tenho investido nela, acompanhando suas transformações e modos de demarcar meus novos devires. (PEREIRA, 2000, p. 38).

Nessa perspectiva, buscamos compreender como se apresentam as Marcas Formadoras, observando de que modo às alunas e alunos descrevem como ocorreram seus processos de aprendizagem em seu cotidiano, ou na educação formal, e como as questões identitárias, pessoais, profissionais, podem influenciar ou não sua constituição como profissionais da educação. Isso, através da descrição de suas experiências e do modo como narram suas histórias individuais e relacionam com suas práticas escolares, ou seja, pelo seu olhar de como se significam como professoras e professores.

\section{Os Memoriais de formação}

Esta investigação se aproxima de uma percepção da vida como expressão criadora, uma pessoa que revela um ponto de vista, entre inúmeros outros, sobre o que possa representar sua trajetória e suas múltiplas interpretações. Com o tema surge a intenção de conhecer sobre como revisitar sua história a partir do tema da escrita do memorial e sua importância na formação dos professores, bem como o que se revela nos memoriais das alunas e dos alunos. Josso (2012, p. 11) nos fala sobre o trabalho biográfico centrado na compreensão:

É no decorrer desse trabalho, articulando respectivamente o presente com o passado, que pode começar a ser elaborado "um projeto de si dentro de um projeto de vida" por um sujeito que orienta o prosseguimento de sua história com uma consciência aguda de seus recursos e fragilidades, de suas valorizações e representações, de suas expectativas, desejos e projetos, de seus alívios e de seus espaços de liberdade em relação a seu próximo e a seus irmãos e irmãs em humanidade.

Segundo Severino (2000, p.175) o Memorial "se constitui numa autobiografia, histórica e reflexiva. Deve ser composto sob a forma de relato histórico, analítico e crítico, que dê conta dos fatos e acontecimentos que constituíram a trajetória acadêmico-profissional de seu autor”. Nas palavras de Soligo e Prado (2005, p. 07):

Um memorial de formação é um gênero textual predominantemente narrativo, circunstanciado e analítico, que trata do processo de formação num determinado período - combina elementos de textos narrativos com elementos de textos expositivos (os que apresentam conceitos e ideias, a que geralmente chamamos 'textos teóricos'). Se tomarmos em conta a definição mais clássica dos tipos de discurso 
- narrativo, descritivo e argumentativo -, poderíamos dizer então que o memorial de formação é um gênero que comporta todos eles, embora evidentemente predomine o discurso narrativo. Em se tratando do estilo, também há lugar para diferentes possibilidades: a opção pode ser por um tratamento mais literário, ou mais reflexivo, ou pela combinação de ambos.

Neste sentido, relacionamos o trabalho biográfico, realizado nas escritas encontradas nos memoriais, com o processo de formação, e buscamos entender categorias, tais como: o surgimento do desejo de ser professor; as opções de entrada na profissão e opções pelo curso de graduação; as representações sobre a profissão, comentários sobre como foi a experiência de escrever o memorial. Analisaremos estas categorias a seguir.

Com a alfabetização surgem as primeiras professoras, com recordações da ternura de sua voz, do carinho ao ensinar a lição, a influência desta para alcançar "boas notas", a ideia de ser ótima aluna, enfim, a admiração pelas educadoras como surgimento do desejo de ser o que elas são. A visão de ser professora como um ser admirável e amável, profissionais que marcaram significativamente, como um espelho do que quero ser, o modo de tratar, de se relacionar, de encorajar, de mostrar possibilidades, de respeito à alteridade. Por outro lado, uma vida escolar com muitas dificuldades nas aprendizagens, não conseguir aprender a ler, humilhações na sala de aula, colegas que debocham e agridem fisicamente. Para uns a escola como lugar de paraíso, para outros como um espaço de superação.

Sobre o desejo de ser professor, observamos que tem relação com as vivências positivas em sua escolarização inicial, seja por perceberem seu crescimento intelectual e pessoal conforme avançam nos estudos, seja por memórias de modelos de professores com atitudes que foram acolhedoras e positivas. Então, com base nas experiências iniciais vividas, nas recordações de educadores, de frustações e de superações, surge o impulso inicial da escolha pela docência, como notaremos nas palavras destas alunas e destes alunos:

Assim foram começando a aparecer uns sintomas de querer seguir a vida lecionando, tanto por tentar ensinar e perceber que as pessoas entendiam, como por brincar bastante de escolinha. Mas essa vontade não duraria muito tempo, a razão inicial talvez pela frustração de alguns dos meus professores depois apenas por realmente não gostar mais de pensar na vida dando aula. Aos dez anos de idade quis mudar de escola e voltar a estudar no mesmo colégio que minha irmã do meio, não por algum motivo pessoal, mas apenas pela razão de que a nova escola oferecia uma viagem de formatura para os alunos da quarta série e então eu queria mudar e viajar sem meus pais. (Depoimento de L.B.C., memorial de formação, Catalão 2015)

Tornei-me universitário e devido o curso exigir dedicação em tempo integral, tive que abandonar o trabalho. Fiquei maravilhado com os professores, pessoas espetaculares com conhecimento profundo dos mais impensáveis assuntos, era mesmo um mundo novo. Comecei a fazer planos, ser professor começou a passar de possibilidade para algo desejável. Assim que pipocou o termo de escolha em minhas mãos, para bacharel ou bacharel-licenciatura integrado 
não pensei duas vezes. Quero ser tudo que a universidade puder me proporcionar, quero ser alguém que ajude os outros a se construírem em vida, como pessoas. (Depoimento de M.V.C.A., memorial de formação, Catalão 2015)

Segundo Bolívar (2007), cada um conhece e ao mesmo tempo desconhece melhor do que ninguém a sua própria vida. Através de uma atividade reflexiva, como o memorial, é possível perceber o que é construído ao longo da formação, na qual, os saberes sobre si mesmo são ao mesmo tempo o objeto e o objetivo da formação, que são consequências de aprendizagens e experiências elaboradas neste caminho. Percebe-se nas narrativas uma mudança ao experimentar a vivência de uma educação formal. Pode ser determinante a opção de entrada na profissão docente, bem como os desdobramentos pela opção do curso superior. Ali, a pessoa já não é mais a mesma. Estas escolhas podem ter sido por influencias da família ou pela compreensão sobre si mesmo, que se transformou ao longo do tempo, como nos depoimentos a seguir:

Minha perspectiva sobre a escola mudou muito ao longo do tempo, se antigamente eu via que ir para a escola era divertido hoje eu vejo que foi o melhor que meu pai e minha mãe poderiam deixar para mim, ficando atrás apenas de minha própria vida. Quando o colégio exigia que os alunos utilizassem um uniforme social eu não gostava daquele uniforme, sendo que na verdade isso era para os alunos aprenderem a se vestir de acordo com o ambiente que tivessem que estar. Nem eu nem qualquer criança queríamos que o professor chamasse a nossa atenção pois se não nossos pais nos davam bronca, também não gostávamos de fazer tarefa de casa e ter que nos comportarmos corretamente na escola. (Depoimento de B.G.A.R., memorial de formação, Catalão 2015)

Diversas experiências tenho vivido hoje, todas me proporcionando grande crescimento, a universidade, em si a própria pedagogia tem feito eu ter um olhar mais amplo de uma futura profissional e fazer a diferença. Em todo esse processo de escolarização, e todo o seu percurso tive diversas experiências, por ter passado por várias escolas. Isso me proporcionou um olhar diferente em vários aspectos, quanto na aprendizagem de minha formação como pessoa, e refletindo sobre e vendo onde estou hoje, todo o processo de mudança de escola quando de cidade mesmo por um curto prazo me faz encarar hoje com mais facilidade as mudanças. Estar em Catalão sem o aconchego da família, mesmo que seja difícil, as dificuldades que passo me faz sonhar cada vez mais alto me fazendo acreditar que amanhã será melhor, e que se mais mudanças vier estarei esperando para vencer os desafios da vida. (Depoimento de I.J.R.O., memorial de formação, Catalão 2015)

O aprender é perspectivado como etapa vencida da vida e como conquista de autonomia. Muitos memoriais colocam as dificuldades econômicas, emocionais e de aprendizagem que sofreram, barreiras até chegar no curso de graduação. Demonstram que mudaram suas atitudes e visão de mundo, tornaram-se pessoas mais reflexivas, prestando mais atenção em tudo que acontece ao seu redor. Consideram a universidade como o lugar no qual começou a fazer o que realmente o preenchesse $\mathrm{e}$ que proporcionasse paz de espírito. 
Nóvoa e Finger (2010, p. 24) afirmam que "o método biográfico permite que cada pessoa identifique na sua própria história de vida aquilo que foi realmente formador". Através do registro da escrita de si mesmo como uma atividade ao mesmo tempo individual e coletiva, isso visa, mesmo que de forma indireta, compreender como se tornar professor. A elaboração do Memorial desperta a memória profissional, traz à luz as experiências formadoras e reflete sobre o processo de formação e as representações sobre a profissão. Ora, isso é possível perceber nos depoimentos abaixo:

Com um olhar de historiadora, busquei fragmentos do meu passado que pudessem influenciar na minha escolha pela História. Através de personagens de meus livros favoritos, vi sombras e rastros do que fui e sou, e com os olhos do presente, busquei interpretá-las, darlhes um sentido. Por vezes, iniciei meu rascunho com um propósito em mente, e deixando a escrita e o pensamento fluírem, cheguei a um final completamente diferente, assombrando-me com novas descobertas. Pensar sobre minha vida acadêmica foi algo mais delicado, pois é uma memória recente do ano passado, o ano de 2014, que foi intenso e transformador para minha vida. Mudanças espirituais, pessoais, profissionais. "É que o quadro que se descortina sob nossos olhos estava carregado de uma significação que permanecia obscura para nós, porém da qual pressentíamos alguma coisa." (Halbwachs, 1990, p. 52) (Depoimento de A.P.F.S., memorial de formação, Catalão 2015)

Estar numa Universidade de algum modo já nos obriga a desconstruir uma série de pensamentos e crenças; e sendo aspirante à Psicóloga me vi nessa necessidade de desconstruir alguns saberes e também construir um pensamento mais crítico sobre o que nos é dado. (Depoimento de L.S.O., memorial de formação, Catalão 2015)

$\mathrm{Na}$ escrita dos memoriais, os alunos desenvolvem a história de formação, sua trajetória de escolarização, ressaltando suas memórias e os aspectos que norteiam os significados que hoje tem em sua vida. Tem a oportunidade de rever algumas posturas. Diante desse processo de revelação de fragmentos de suas memórias, que por algum motivo ficaram marcados e levaram ao questionamento das suas escolhas nas suas vivências tanto na escolarização, quanto na profissionalização e, até mesmo, na vida particular, eles tecem comentários sobre como foi a experiência de escrever o Memorial, como nas descrições a seguir:

Nessa perspectiva, percebo o quão enriquecedor vem a ser este processo de escrita do memorial para a minha formação pedagógica, pois me faz buscar informações no passado atrelando-as ao presente a fim de dar um sentido à construção de minha história. Entendo que o memorial não é uma simples narrativa do passado, é sim uma experiência enriquecedora que me permite voltar ao passado, lançando um novo olhar sobre os caminhos percorridos, refletindo sobre as decisões tomadas a fim de ressignificar a minha história e minha trajetória de vida. (Depoimento de A.A.M., memorial de formação, Catalão 2015)

Desta feita, o processo de escrita do meu memorial se constitui como um importante exercício para minha formação acadêmica, pois, ao descrever minha história de vida, fui dando novos sentidos aos fatos ocorridos no meu passado, relembrando pontos que foram 
pouco destacados na minha trajetória, refletindo sobre minhas vivências e experiências e dando novos sentidos ao meu presente. Assim, fui construindo minhas narrativas biográficas, viajando através da memória e do tempo, a espaços e momentos que fizeram parte de toda minha trajetória de formação, levando-me a reorganizar tais lembranças a fim de auxiliar no meu processo de formação docente e refletindo sobre a educação que temos e a educação que queremos. (Depoimento de F.G.F., memorial de formação, Catalão 2015)

A escolha para o curso superior para todos foi significativo, com dúvidas e com angustia, mas um momento de tomada de decisão em suas vidas. Alguns não conseguiram seguir o seu desejo inicial, outros trocaram de curso, ambos, por motivos diversos. Mas todos se dizem satisfeitos com sua escolha atual. Alguns se perguntam sobre o tipo de professor que querem ser, talvez como uma referência muito importante quanto à motivação para os alunos, como podemos observar nos depoimentos a seguir:

Como futura educadora decidi colocar a escrita de Passeggi em prática, quando a autora fala da importância de investigar o ponto de vista desses profissionais, para entendermos como eles constroem a "autoconsciência" das mudanças necessárias para o processo formativo e a construção do meu próprio "processo identitário". Para fazer isso contarei sobre o decorrer da minha vida acadêmica, minhas inspirações e dúvidas, que me fizeram chegar onde estou e minhas pretensões futuras. (Depoimento de B.A., memorial de formação, Catalão 2015)

Com a escrita do Memorial, pude entender um pouco da minha própria história e que antes não teria feito se quer alguma relação de onde estou em minha formação e o porquê de estar. Foi um conhecimento diferente de tudo aquilo que já havia passado, principalmente na faculdade, por cursar Engenharia e durante as aulas não ter um tipo de "debate" ou conversa sobre a vida, apenas muito cálculo e física aprofundados. (Depoimento de L.B.C., memorial de formação, Catalão 2015)

A escrita do memorial é compreendida como contribuições do passado; momento importante; exercício de escrita como compreensão de um processo; recordar memórias de experiência vividas ou ouvidas; novos significados do que foi vivido para a formação acadêmica e humana. Ao escrever o memorial, o sujeito reconhece como uma fase importante de sua vida escolar. O prazer em escrever o memorial, enfim, a escrita do memorial aparece como incentivo para ser uma professora que mude a realidade. Podemos compreender as histórias de vida como ensinamentos preciosos gravados na memória, percepção de um crescimento pessoal, passagens marcantes da trajetória de quem arrisca escrever sobre o seu passado e se arrisca a vivenciar momentos que estavam guardados. Tantas colocações sobre o processo de escrita que podem ser traduzidas nestas palavras:

Vejo que o prazeroso de escrever este memorial é justamente deixar que o narrador teça os fios que entrelaçam os fatos entre si, e mostrando o que e como os fatos provocaram efeitos formadores, seja na vida pessoal, intelectual ou profissional. Desse modo, acredito que a finalidade em escrever sobre minhas próprias aprendizagens é justa- 
mente poder situar como foi o meu processo formador ao longo de minha vida. E com a escrita desse memorial vejo a necessidade de ser uma professora que faça a diferença, que mude a realidade dos alunos. Assim, considero os memoriais instrumentos pedagógicos de real valia, uma vez que os professores podem rever as suas práticas, refletir sobre elas e planejar novas ações para o futuro. (Depoimento de T.D.S., memorial de formação, Catalão 2015)

O memorial possui o intuito de buscar nas lembranças a compreensão da trajetória de vida do sujeito, procurando entender o que o levou a ser quem ele é e o porquê de ter feito algumas escolhas, como por exemplo, da sua formação. $\mathrm{O}$ mesmo é feito por meio de narrativas autobiográficas, que são construídas através de autorreflexões que fazem com que o narrador venha selecionar os fatos que são importantes e que vão surgindo através de conversas com outros que também estejam contando a sua história de vida. (Depoimento de L.B.C., memorial de formação, Catalão 2015)

Sobre o compartilhamento de saberes e de vivências, nas palavras de Fontana (2006, p. 233):

Narrar pressupõe uma comunidade de vida e de discurso entre o narrador e o ouvinte, fundada em uma tradição e memória comuns, ligadas a um trabalho. Aquele que narra (com)partilha saberes e vivências nos quais seus ouvintes se re-conhecem e pelo re-conhecimento, inserem-se na história que está sendo narrada, fazendo sugestões sobre sua continuação, vivendo esta continuação.

Com relação às narrativas, como práticas discursivas e suas possibilidades de aproximação com dinâmicas nos processos de formação como portadoras de saberes, sonhos, emoções, sentimentos experimentados de angústia e de raiva, que podem escapar a uma percepção objetiva, mas estão presentes nas tramas e dramas relatados, neste compartilhamento, reside sua possibilidade de inúmeras interpretações, pode-se dizer que uma história leva a outra.

\section{Considerações}

A presente pesquisa realizou uma investigação sobre a relação entre Marcas Formadoras e a produção de Memoriais de Formação. Buscamos socializar os resultados da pesquisa realizada no Estágio de Pós-Doutorado, intitulada "Histórias de Vida e Biografização: Memoriais de Alunas do Curso de Pedagogia da UFG/Regional Catalão - 2015". O problema de pesquisa foi a análise do sentido das marcas formadoras que profissionais da educação em formação produzem quando são submetidos à escrita de memoriais.

A partir das leituras das narrativas evidenciou-se a relação entre memória e formação docente e observamos algumas marcas formadoras e sua influência na construção identitária dos educadores, através de categorias, tais como: o surgimento do desejo de ser professor; as opções de entrada na profissão e opções pelo curso; as representações sobre a profissão e comentários sobre como foi a experiência de escrever o memorial. 
Como principais conclusões constatamos que o Memorial de Formação foi um instrumento de diálogo entre nós e as alunas e os alunos, uma autoavaliação sobre os avanços conseguidos em suas vidas, sobre as dificuldades encontradas, sobre os conhecimentos apreendidos, sobre suas angústias e suas expectativas. O relato de formação dos sujeitos desta pesquisa tornou explícito e visíveis os conhecimentos, as experiências e os percursos de como sua identidade profissional foi se constituindo. A escrita desta narrativa permitiu relatar os acontecimentos importantes da vida acadêmica e fazer uma reflexão a partir deles sobre de que forma sofremos influencias em nossa prática educativa e da origem de nossas escolas.

Observamos que a narrativa dos educadores em formação demonstraram que ao experimentar a vivência de uma educação formal, a pessoa passa por uma transformação de seus valores, de seu modo de ser, passa a perceber o mundo e as pessoas de outra maneira. Ao escrever seus relatos, tiveram a oportunidade de refletir sobre a construção do seu processo de escolarização. Ao realizar escolhas sobre a relevância de certos momentos dentro de um contexto maior e buscar um significado novo hoje em um outro momento, ao se distanciar do seu processo de formação para repensá-lo, encontramos marcas do passado, de suas memórias, de seus sentimentos sobre como aconteceram e de que hoje estas lembranças/vivências fazem de nós quem somos.

Ao concluir esta pesquisa pensamos que a escrita dos memoriais possibilitaram, entre outros aspectos, uma descoberta de como as escolhas profissionais, as vivências de sua formação acadêmica, e, até mesmo as relações com as pessoas determinam e ao mesmo tempo são contingências que podem definir quem somos e o que fazemos no mundo sempre em constante movimento. Este veio de pesquisa, como tantos outros, não deixa uma resposta, como uma certeza inabalável. Ao contrário, suscita muito mais perguntas, num processo infindável da compreensão do ser humano. Especialmente aquele, ou aquela, que em algum momento da vida teve o desejo e buscou a profissão de professor, professora.

\section{Referências}

ABRAHÃO, M. H. M. B. (Orgs.); JOSSO, Marie-Chistine - Prefácio. Tempos, narrativas e fiç̧ões: a invenção de si. Porto Alegre: EDIPUCRS, 2006.

ABRAHÃO, M. H. M. B. Memoriais de formação: a (re)significação das imagens-lembranças/ recordações-referências para a pedagoga em formação. Educação, Porto Alegre, v. 34, n. 2, 2011, p. $165-172$.

BOLÍVAR, A. Educación para la Ciudadanía. Algo más que una asignatura. Barcelona: Grão, 2007.

BOLZAN, D. P. V. Pedagogia Universitária e processos formativos: a construção do conhecimento pedagógico compartilhado. In: Eggert; Traversini; Peres; Bonin. (orgs.). Trajetórias e processos de ensinar e aprender: didática e formação de professores. Ed. Porto Alegre: EDIPUCRS, v. 1, p. 102-120, 2008.

BOLZAN, D. P. V. A construção do conhecimento Pedagógico compartilhado: um estudo a partir de narrativas de professoras do ensino fundamental. Porto Alegre: Faculdade de Educação, UFRGS, 2001. 
BOLZAN, D. P. V. Formação de professores: compartilhando e reconstruindo conhecimentos. Porto Alegre: Mediação, p.174, 2002.

DELORY-MOMBERGER, C. Abordagens metodológicas na pesquisa biográfica. Universidade de Paris 13. Tradução de Anne-Marie Milon Oliveira Revisão técnica de Fernando Scheibe. Revista Brasileira de Educação. v. 17. n. 51. set.-dez. 2012.

FERREIRA, N. R. S. Currículo: espaço do professor na escola de educação Básica. Revista Interd., São Paulo, Volume 1, número 0, p.01-83, Out, 2010.

FINGER, M. As implicações socioepistemológicas do método biográfico. In NÓVOA, A., FINGER, M. O método (auto)biográfico e a formação. Natal, RN: EDUFRN; São Paulo: Paulus, 2010.

JOSSO, M. Caminhar para Si. Tradução Albino Pozzer; coord. Maria Helena Menna Barreto Abrahão. Porto Alegre: EDIPUCRS, 2010a.

JOSSO, M. Da formação do sujeito... ao sujeito da formação. In: NÓVOA e FINGER (org.). O método (auto)biográfico e a formação. Nata, RN: EDUFRN; São Paulo: Paulus, 2010b.

JOSSO, M. A transformação de si a partir da narração de histórias de vida. Educação, Porto Alegre, ano 30, n. 3 (63), set./dez. 2007.

JOSSO, M. Os relatos de histórias de vida como desvelamento dos desafios existenciais da formação e do conhecimento: destinos sócio-culturais e projetos de vida programados na invenção de si. In: SOUZA, Elizeu Clementino de; ABRAHÃO, Maria Helena Menna Barreto (Org.). Tempos, narrativas e ficções: a invenção de si. Porto Alegre: EDIPUCRS; Salvador: EDUNEB, 2006a.

JOSSO, M. As figuras de ligação nos relatos de formação: ligações formadoras, deformadoras e transformadoras. Educação e Pesquisa, São Paulo, v.32, n.2, p. 373-383, maio/ago. 2006 b.

JOSSO, M. Experiências de vida e formação. São Paulo: Cortez, 2004.

NÓVOA, A.; FINGER, M. (Org.). O método (auto)biográfico e a formação. Natal, RN: EDUFRN; São Paulo: Paulus, 2010.

PASSEGGI, M. da C., SOUZA, E. Clementino de; VICENTINI, Paula Perin. Entre a vida e a Formação: Pesquisa (auto)biográfica, docência e profissionalização. Educação em Revista. Belo Horizonte, v.27, n.01, p. 369-386, abr. 2011.

PASSEGGI, M. C.. Memoriais de formação: processos de autoria e de (re)construção identitária. In: CONFERÊNCIA DE PESQUISA SÓCIO-CULTURAL, 3. 2000. Anais. Campinas, Disponível em: <http://www.fae.unicamp.br/br2000/trabs/1970.doc >. Acesso em: 28 jun. 2015.

PEREIRA, M. V. Nos supostos para pensar formação e autoformação: a professoralidade produzida no caminho da subjetivação. In: Ensinar e aprender: sujeitos, saberes e pesquisa. Rio de Janeiro: DP\&A, 2000. Trabalho apresentado no 1. ENDIPE.

PINEAU, G. A autoformação no decurso da vida: entre a hetero e a ecoformação. In: PINEAU, G.; NÓVOA, A.; FINGER, M. O método (auto)biográfico e a formação. Lisboa. Ministério da Saúde/Departamento de Recursos Humanos, 1988.

SEVERINO, A. J. Metodología do trabalho científico. 21.ed. rev. ampl. São Paulo: Cortez, 2000.

SOLIGO, R. e PRADO, G. T.. Memorial de formação - quando as memórias narram a história de formação, Disponível em: http://www.fe.unicamp.br/ensino /graduacao/downloads/ proesf- memorial GuilhermePrado_RosauraSoligo.pdf. Acesso em março de 2015.

FONTANA, R. A. C. Contar a vida - possibilidades e contribuições dos relatos de experiência e das histórias de vida para o estudo dos processos de formação de professores. In: SOUZA, E. C. de; SOUSA. (Org.). Autobiografias, história de vida e formação: pesquisa e ensino. Porto Alegre: EDIPUCRS, 2006. 
Histórias de vida e biografização: pesquisa sobre as marcas formadoras de professores da região sudeste do estado de Goiás através dos memoriais de formação

SANTAMARINA, C. e MARINAS, J. M. Historias de vida y historia oral. In DELGADO, J. M. e GUTIÉRRES, J. Métodos y técnicas cualitativas de investigación en ciencias sociales. Madrid: Síntesis, 1994.

SOUZA, E. C. de. Biografar-se e empoderar-se: entrevista Autobiográfica-narrativa e percursos de formação da professora Dilza Atta. In: ABRAHÃO, Maria Helena Menna Barreto (Orgs.). Destacados Educadores riogradenseses. Porto Alegre: EDIPUCRS, 2016.

SOUZA, E. C. de. Narrativas, estágio supervisionado e formação inicial de professores. In: BARBOSA, Raquel Lazzani Leite Barbosa (Orgs.). Formação de Educadores - Artes e Técnicas - Ciências e Pólíticas. São Paulo: Editora UNESP, 2006.

\section{Notas}

1 Além de alunas do Curso de Pedagogia, haviam também alunos e alunas de outras licenciaturas, tais como Geografia, Psicologia, Ciências Sociais, História, etc.

* Professora da Rede Pública Municipal de Porto Alegre e Aluna de Estágio Pós-doutoral, no Programa de Pós-Graduação em Educação da Universidade Federal de Goiás, Catalão, Goiás, Brasil.

** Professor da Universidade Federal de Goiás, Unidade Acadêmica Especial - Educação e do Programa de Pós-Graduação em Educação, Catalão, Goiás, Brasil.

\section{Correspondência}

Wolney Honório Filho - Universidade Federal De Goiás - Regional Catalão, Unidade Acadêmica Especial Educação - UAE-E. Av. Lamartine Pinto Avelar, 1120, Bloco I - Setor Universitário. CEP: 75704020. Catalão, Goiás, Brasil.

E-mail: clau.machadors@uol.com.br-whonoriof@gmail.com

Recebido em 06 de julho de 2016

Aprovado em 20 de dezembro de 2017 
